\title{
Oxidation of ferrocene derivatives at a poly[Ni(saltMe)] modified electrode
}

\author{
M. Vilas-Boas ${ }^{\mathrm{a}, 1}$, E.M. Pereira ${ }^{\text {a }}$, C. Freire ${ }^{\mathrm{a}, *}$, A.R. Hillman ${ }^{\mathrm{b}, *}$ \\ ${ }^{\text {a } C E Q U P / D e p a r t a m e n t o ~ d e ~ Q u i ́ m i c a, ~ F a c u l d a d e ~ d e ~ C i e ̂ n c i a s, ~ U n i v e r s i d a d e ~ d o ~ P o r t o, ~ R u a ~ d o ~ C a m p o ~ A l e g r e, ~ 687, ~ 4169-007 ~ P o r t o, ~ P o r t u g a l ~}$ \\ ${ }^{\mathrm{b}}$ Department of Chemistry, University of Leicester, Leicester LE1 7RH, UK
}

Received 8 February 2002; received in revised form 4 July 2002; accepted 20 July 2002

\begin{abstract}
The characterisation of film permeability and mediation properties of poly[Ni(saltMe)] modified electrodes were evaluated by studying the oxidation of ferrocene and 1,1'-dimethylferrocene at these electrodes by rotating-disk voltammetry. The effects of varying the substrate and its solution concentration, film thickness, rotation speed and electrode potential on the limiting current density were analysed using the model of Albery. Both substrate oxidations show two mechanisms, according to the applied potential. The first, direct reaction on the underlying electrode is controlled by substrate transport through the film (Et $\mathrm{S}_{\mathrm{S}}$ case). The second, polymer-mediated reaction occurred at higher potentials, and was the only substrate oxidation process observed for thick films. Mechanistic analysis for polymer-mediated oxidation revealed some dependence of the reaction zone on the substrate and its concentration. For the highest ferrocene concentrations, oxidation occurs in a thin reaction layer away from both interfaces (LRZt $\mathrm{t}_{\mathrm{s}}$ case). However, for the highest concentrations of 1,1'-dimethylferrocene, the mediated reaction is controlled by substrate transport through the film and occurs close to the underlying electrode interface ( $\mathrm{LEt}_{\mathrm{S}}$ case). As both substrate concentrations decrease, the heterogenous rate constants for the modified electrode, $k_{\mathrm{ME}}^{\prime}$, become essentially independent of film thickness and are consistent with rate limiting electron transfer at or near the film $\mid$ solution interface (S $k^{\prime}$ or LS $k$ cases).
\end{abstract}

(C) 2002 Elsevier Science B.V. All rights reserved.

Keywords: Rotating disk electrode (RDE); Kinetic model; Electrocatalysis; Redox reaction; Chemically modified electrode

\section{Introduction}

Complexes of nickel with tetradentate ' $\mathrm{N}_{2} \mathrm{O}_{2}$ ' Schiff base ligands based on salicylaldehyde have interesting redox properties that offer potential applications in electrocatalytic oxidations. In strong donor solvents, the axial ligand positions are occupied by solvent and the complexes generally show reversible redox chemistry based on the $\mathrm{Ni}(\mathrm{II} / \mathrm{III})$ couple [1-6]. Contrastingly, in solvents of low donor number, oxidation of the complexes can lead to polymerisation and deposition of this polymer on the electrode [7-19]. The result is then a

* Corresponding authors. Tel.: +351-22-608-2890; fax: +351-22608-2959 (C.F.); Tel.: +44-116-252-2144; fax: +44-116-252-5227 (R.H.)

E-mail addresses: acfreire@fc.up.pt (C. Freire), arh7@le.ac.uk (A.R. Hillman).

${ }^{1}$ Present address: Escola Superior Agrária de Bragança, 5300-855 Bragança, Portugal. polymer modified electrode, which one might hope possesses the interesting and useful properties of the monomer-but with the advantage of direct electrochemical control of the redox state-and which one might anticipate exhibits some new properties associated with the polymerisation process and surface immobilisation.

A number of studies of poly[M(salen)]-type complexes have been reported [7-19], most of which have focused on aspects of film polymerisation and characterisation. In our studies of poly[Ni(salen)] [16] and poly[Ni(saltMe)] [17-19], we have used cyclic voltammetry $(\mathrm{CV})$ and chronoamperometry to study film redox activity and charge transport, UV-vis, FTIR and EPR spectroscopies to explore aspects of electronic structure, and the electrochemical quartz crystal microbalance (EQCM) and probe beam deflection (PBD) to characterise ion and solvent transfer processes driven by redox switching. 
The above studies have provided insights into: (a) the sources and sinks of electronic charge that can drive redox processes; and (b) electron and ion transport rates within the film, in each case in the absence of electroactive species in solution. With this information, we are now in a good position to add a solution redox couple to which the film may mediate charge transfer. In this study we do so for model solution redox couples based on ferrocene. We use the applied potential to control the supply of electronic charge at the electrode | polymer interface and the rotating disk electrode (RDE) hydrodynamics to control the supply of reactant at the polymer|solution interface. Based on a model of modified electrode kinetics and transport independently developed by Albery and Hillman [20,21] and Savéant and coworkers [22-24], we are able to establish the mechanism of both direct and mediated charge transfers and to show how variation of experimental parameters influences mechanism and rate. This information will be valuable in future design of poly[M(salen)]-type modified electrodes.

The charge transfer process of any solute species at a modified electrode may occur in several regions, subject to the chemical and physical properties of the film and substrate. These parameters can be described through the reaction zone thickness, that is controlled by the distance that electrons can travel from the electrode across the film, $X_{0}$, and by the distance that the solute can travel from the solution towards the electrode interface, $X_{\mathrm{d}}$, before they react $[20,21]$ :

$$
\begin{aligned}
& X_{0}=\left(\frac{D_{\mathrm{e}}}{k \kappa c_{\mathrm{S}}}\right)^{1 / 2} \\
& X_{\mathrm{d}}=\left(\frac{D_{\mathrm{SP}}}{k b_{0}}\right)^{1 / 2}
\end{aligned}
$$

where $D_{\mathrm{e}}$ represents the diffusion coefficient for electrons, $D_{\mathrm{SP}}$ the diffusion coefficient of the substrate in the film, $k$ is the constant rate for the mediated reaction, $k$ is the partition coefficient, $c_{\mathrm{S}}$ the substrate concentration at the film $\mid$ solution interface and $b_{0}$ represents the mediator concentration within the film. Depending on the relative rates of the kinetic and transport processes, the reaction could occur closer to the film | solution interface (if electrons travel faster than solute) or the underlying electrode $\mid$ film interface (if solute travels faster than electrons), in each case under conditions of either kinetic or diffusion control. Fig. 1 shows the possible situations for different combinations of kinetic and transport parameters and expressions defining the heterogenous rate constants for the modified electrode for each case, $k_{\mathrm{ME}}^{\prime}[20,21]$. Here we use ferrocene-based solution species as redox probes for poly[Ni(saltMe)] modified electrodes and apply the Albery model [20,21] to explain the observed membrane/mediator properties.

\section{Experimental}

\subsection{Materials}

The complex 2,3-dimethyl- $N, N^{\prime}$-bis(salicylidene)butane-2,3-diaminato-nickel(II), [Ni(saltMe)], was prepared using a procedure described in the literature [4], and recrystallised from $\mathrm{MeCN}$. Tetraethylammonium perchlorate, TEAP (Fluka, puriss.) was used as received and dried in an oven at $60{ }^{\circ} \mathrm{C}$ prior to use. Acetonitrile (Fisons, HPLC grade) was refluxed twice over $\mathrm{CaH}_{2}$ and distilled under Ar before use. The substrates, ferrocene $(97 \%)$ and 1,1'-dimethylferrocene $(98 \%)$ were purchased from Aldrich and used as received.

\subsection{Instrumentation}

Electrochemical measurements were performed using an Autolab PGSTAT20 potentiostat/galvanostat. The electrochemical cell was a closed standard three-electrode cell that was connected to a solution reservoir through a teflon tube. A platinum disk electrode (Radiometer EDI 101) with an area of $0.0314 \mathrm{~cm}^{2}$ was used as the working electrode (WE) and a Pt gauze electrode as the counter electrode. The electrode rotation speed was regulated with a Radiometer CTV 101 speed controller. All potentials refer to an $\mathrm{Ag} \mid \mathrm{AgCl} 1$ mol dm ${ }^{-3} \mathrm{NaCl}$ reference electrode. Prior to use, the $\mathrm{Pt}$ WE was polished with an aqueous suspension of 0.05 $\mu \mathrm{m}$ alumina (Beuhler) on a Master-Tex (Beuhler) polishing pad, then rinsed with water and $\mathrm{C}_{3} \mathrm{H}_{6} \mathrm{O}$ and dried in the oven. All solutions were de-oxygenated and delivered to the cell by a stream of Ar.

\subsection{Procedures}

Poly[Ni(saltMe)] films were deposited by cycling the potential of the WE between 0.0 and $1.3 \mathrm{~V}$ at $0.1 \mathrm{~V} \mathrm{~s}^{-1}$, immersed in a $\mathrm{CH}_{3} \mathrm{CN}$ solution containing $1 \mathrm{mmol}$ $\mathrm{dm}^{-3}\left[\mathrm{Ni}\right.$ (saltMe)] monomer and $0.1 \mathrm{~mol} \mathrm{dm}{ }^{-3}$ TEAP. Films of different thickness were prepared by using different numbers of potential cycles; a coulometric assay in monomer-free solution for each film yielded the relevant polymer electroactive surface coverage, $\Gamma(\mathrm{mol}$ $\mathrm{cm}^{-2}$ ), on the basis that one positive charge is delocalised over each monomer unit [18]. The voltammograms used in the calculation of the electroactive surface coverage were performed at $0.01 \mathrm{~V} \mathrm{~s}^{-1}$, to ensure that the oxidation/reduction processes occur throughout the whole film.

After electropolymerisation, the modified electrode was thoroughly rinsed with dry $\mathrm{CH}_{3} \mathrm{CN}$ and immersed in $0.1 \mathrm{~mol} \mathrm{dm}{ }^{-3} \mathrm{TEAP}+\mathrm{CH}_{3} \mathrm{CN}$ solution for electrochemical characterisation of the film using $\mathrm{CV}$, between -0.1 or 0.0 and $1.3 \mathrm{~V}$, for $1,1^{\prime}$-dimethylferrocene and ferrocene, respectively, at $0.050 \mathrm{~V} \mathrm{~s}^{-1}$, with and without 
a)

i)
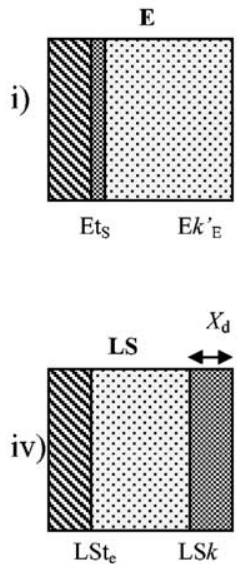

ii)

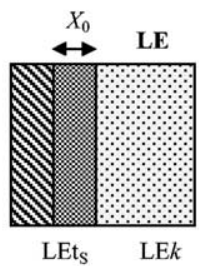

S

v)

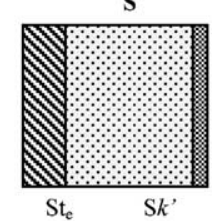

iii)

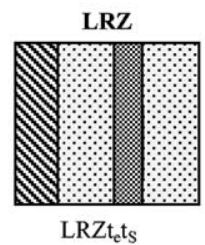

L

vi)

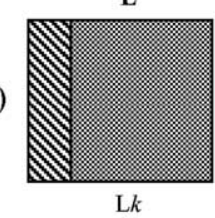

Electrode Reaction zone

b)

\begin{tabular}{|c|c|c|c|}
\hline Case notation & Expression for $k_{\mathrm{ME}}^{\prime}$ & Case notation & Expression for $k_{\mathrm{ME}}^{\prime}$ \\
\hline $\mathrm{Et}_{\mathrm{s}}$ & $\frac{\kappa D_{\mathrm{SP}}}{d}$ & $\mathrm{LSt}_{\mathrm{e}}$ & $\frac{D_{\mathrm{e}} b_{0}}{d c_{\mathrm{S}}}$ \\
\hline $\mathrm{E} k_{\mathrm{E}}^{\prime}$ & $\kappa k_{\mathrm{E}}^{\prime}$ & LS $k$ & $\kappa \sqrt{k b_{0} D_{\mathrm{SP}}}$ \\
\hline $\mathrm{LEt}_{\mathrm{S}}$ & $\frac{\kappa D_{\mathrm{SP}}}{d}$ & $\mathrm{St}_{\mathrm{e}}$ & $\frac{D_{\mathrm{e}} b_{0}}{d c_{\mathrm{S}}}$ \\
\hline LE $k$ & $\kappa b_{0} \sqrt{\frac{D_{\mathrm{e}} k}{c_{\mathrm{S}}}}$ & $\mathrm{s} k^{\prime}$ & $k^{\prime} b_{0}$ \\
\hline $\mathrm{LRZ}_{\mathrm{t}} \mathrm{t}_{\mathrm{s}}$ & $\frac{D_{\mathrm{e}} b_{0}}{d c_{\mathrm{S}}}+\frac{\kappa D_{\mathrm{SP}}}{d}$ & $\mathrm{~L} k$ & $\kappa k b_{0} d$ \\
\hline
\end{tabular}

Fig. 1. (a) Schematic representation of the 10 possible cases for the substrate oxidation reaction zones. (b) Equations defining the heterogeneous rate constant for the modified electrode, $k_{\mathrm{ME}}^{\prime}$

hydrodynamic control. The rotation speed was varied between 500 and $4500 \mathrm{rpm}$. For the oxidation studies of the substrates, the solution was changed to $0.1 \mathrm{~mol}$ $\mathrm{dm}^{-3}$ TEAP $+\mathrm{CH}_{3} \mathrm{CN}$ containing ferrocene or $1,1^{\prime}-$ dimethylferrocene with concentrations in the range $2 \times$ $10^{-4}-2 \times 10^{-3} \mathrm{~mol} \mathrm{\textrm {dm } ^ { - 3 }}$. These studies were also carried out under the same voltammetric and hydrodynamic conditions as mentioned above.

\section{Results}

\subsection{Substrate oxidation on bare electrode}

Ferrocene and 1,1'-dimethylferrocene were chosen as probe redox couples based on two criteria: the need for probe redox couples with well-documented electrochemical behaviour and the opportunity to explore the effect of reactant size/geometry. RDE voltammograms were obtained for the oxidation of these species on a bare $\mathrm{Pt}$ electrode as a function of rotation speed. Analysis of the limiting current density, $j_{\mathrm{L}}$, according to the Levich equation [25] produces diffusion coefficients $D_{\mathrm{S}}^{\mathrm{Me}_{2} \mathrm{Fc}}=2.0 \times 10^{-5} \mathrm{~cm}^{2} \mathrm{~s}^{-1}$ and $D_{\mathrm{S}}^{\mathrm{Fc}}=$ $2.1 \times 10^{-5} \mathrm{~cm}^{2} \mathrm{~s}^{-1}$, close to the literature values [2629].

\subsection{Electrochemical polymerisation and redox switching}

The electrochemical oxidation of [Ni(saltMe)] in $\mathrm{CH}_{3} \mathrm{CN}$ is known to be an irreversible process that leads to film deposition on the electrode surface; polymer coverage can be varied via the number of potential cycles, as described in previous papers $[17,18]$. The electrochemical responses of the modified electrodes in monomer-free solution for two films with different 

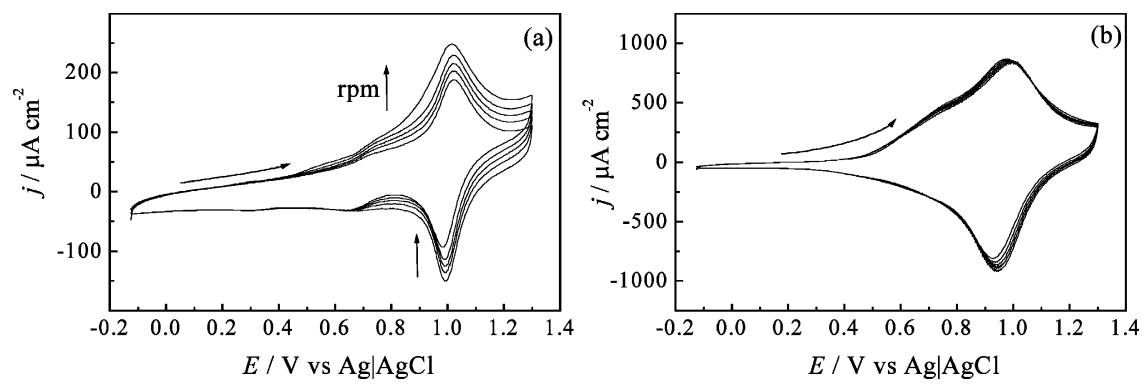

Fig. 2. Cyclic voltammograms with rotation $(500-4500 \mathrm{rpm})$ for the poly[Ni(saltMe)] modified electrode, immersed in $0.1 \mathrm{~mol} \mathrm{dm}^{-3} \mathrm{TEAP}+$

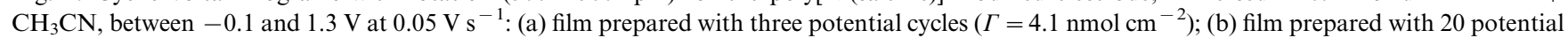
cycles $\left(\Gamma=47 \mathrm{nmol} \mathrm{cm}^{-2}\right)$.

thickness, Fig. 2, exhibit two reversible electrochemical processes at $E_{1 / 2}(\mathrm{I})=0.68 \mathrm{~V}$ and $E_{1 / 2}(\mathrm{II})=0.95 \mathrm{~V}$ that are independent of rotation speed.

\subsection{Substrate oxidation on the modified electrode}

Quite generally the mediated charge transfer reaction can be located in a mechanistic case diagram (Fig. 1): (i) at the electrode | film interface; (ii) in a reaction layer close to the electrode interface; (iii) in a defined zone within the film; (iv) in a reaction layer close to the solution interface; (v) at the film | solution interface; or (vi) throughout the film. The steady state solution mass transport properties offered by the RDE technique allow a simple analysis and a full characterisation of the charge transfer mechanism, based on the limiting current density dependence upon rotation speed, film thickness and solute concentration $[20,21,30,31]$.

\subsubsection{Film thickness dependence}

The voltammograms presented in Fig. $3 a$ and $b$ correspond to typical electrochemical behaviour for either the oxidation of $\mathrm{Me}_{2} \mathrm{Fc}$ or $\mathrm{Fc}$ at a thin poly[Ni(saltMe)] modified electrode. The cyclic voltammogram without rotation, Fig. 3a, shows not only the oxidation/reduction of the polymer around $1.0 \mathrm{~V}$, but also two other electrochemical processes at $E_{1 / 2}(\mathrm{I})=$ $0.28 \mathrm{~V}$ and $E_{1 / 2}(\mathrm{II})=0.42 \mathrm{~V}$ for $\mathrm{Me}_{2} \mathrm{Fc}$ and $E_{1 / 2}(\mathrm{I})=$ $0.38 \mathrm{~V}$ and $E_{1 / 2}(\mathrm{II})=0.56 \mathrm{~V}$ for Fc. Under hydrodynamic conditions these new features appeared as two current density plateaux (Fig. 3b).

The first limiting current density plateau, $j_{\mathrm{L}}(\mathrm{I})$ lies at a potential close to that observed for the oxidation of the solute at uncoated $\mathrm{Pt}$ electrodes, and in a potential region where the polymer shows no electrochemical activity. These observations suggest that the first electrochemical process observed for the oxidation of $\mathrm{Me}_{2} \mathrm{Fc}$ or $\mathrm{Fc}$ at the poly[Ni(saltMe)] modified electrode corresponds to the reaction of the solutes directly on the Pt electrode surface, with the film acting only as a physical barrier.

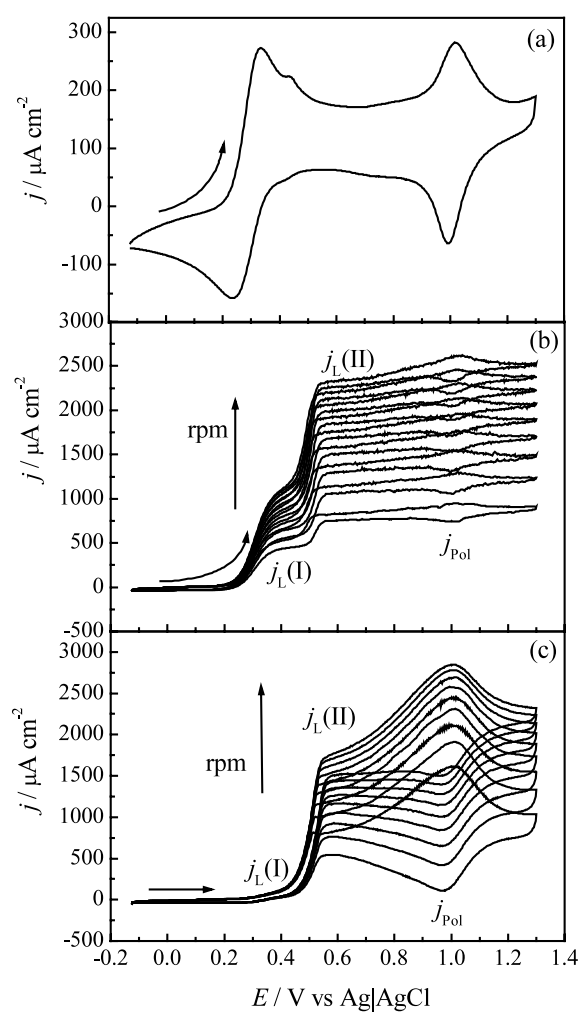

Fig. 3. Typical voltammograms for poly[Ni(saltMe)] modified immersed in a $1.0 \mathrm{mmol} \mathrm{dm}{ }^{-3} \mathrm{Me}_{2} \mathrm{Fc}+0.1 \mathrm{~mol} \mathrm{dm}{ }^{-3} \mathrm{TEAP}+\mathrm{CH}_{3} \mathrm{CN}$ solution, between -0.1 and $1.3 \mathrm{~V}$ at $0.05 \mathrm{~V} \mathrm{~s}^{-1}$ : (a) cyclic voltammogram (without rotation) for a thin film, $\Gamma=4.1 \mathrm{nmol}$ $\mathrm{cm}^{-2}$; (b) steady state voltammograms from 500 to $4500 \mathrm{rpm}$ for the same film; (c) steady state voltammograms from 500 to $4500 \mathrm{rpm}$ for a thick film $\Gamma=47 \mathrm{nmol} \mathrm{cm}^{-2} \cdot j_{\mathrm{L}}$ (I) and $j_{\mathrm{L}}$ (II) correspond to the first and second current density plateaux, respectively, and $j_{\mathrm{Pol}}$ to the current density due to the film oxidation.

The second oxidation process, $j_{\mathrm{L}}$ (II) occurs at higher potentials than the direct reaction $(0.14 \mathrm{~V}$ more positive for $\mathrm{Me}_{2} \mathrm{Fc}$ and $0.18 \mathrm{~V}$ for $\mathrm{Fc}$ ), and at a potential where significant (albeit small) amounts of polymer are oxidised. This is attributed to mediated charge transfer.

Fig. $3 \mathrm{c}$ presents the electrochemical response for the oxidation of $\mathrm{Me}_{2} \mathrm{Fc}$ (similar behaviour is observed for ferrocene) with a thicker poly[Ni(saltMe)] modified 
electrode. Around $0.44 \mathrm{~V}$, where it was expected to observe the direct oxidation of this substrate on the $\mathrm{Pt}$ electrode, the voltammograms shows only a very small shoulder, the intensity of which is independent of the rotation speed. The second plateau persists, showing only a positive potential shift with increasing film thickness. Upon increasing the electroactive coverage (i.e. film thickness), slower solute transport across the film should decrease the rate of direct oxidation. This is exactly what is observed: upon increasing the thickness of the film $\left(\Gamma=4.1-47 \mathrm{nmol} \mathrm{cm} \mathrm{cm}^{-2}\right)$, the first plateau tends to disappear as illustrated by comparison of Fig. $3 \mathrm{~b}$ and $\mathrm{c}$.

\subsubsection{Substrate concentration dependence}

The oxidation of $\mathrm{Me}_{2} \mathrm{Fc}$ and $\mathrm{Fc}$ at poly[Ni(saltMe)] modified electrodes is almost independent of the solute concentrations, over the range $0.2-2.0 \mathrm{mmol} \mathrm{dm}^{-3}$. At all concentrations we see two current density plateaux for thin films $\left(j_{\mathrm{L}}(\mathrm{I})\right.$ and $\left.j_{\mathrm{L}}(\mathrm{II})\right)$ and one for thick polymer films $\left(j_{\mathrm{L}}(\mathrm{II})\right)$, in addition to the polymer-based electrochemistry. As can be observed in Fig. $4 a$ and b, the limiting current plateaux increase with solute concentration.

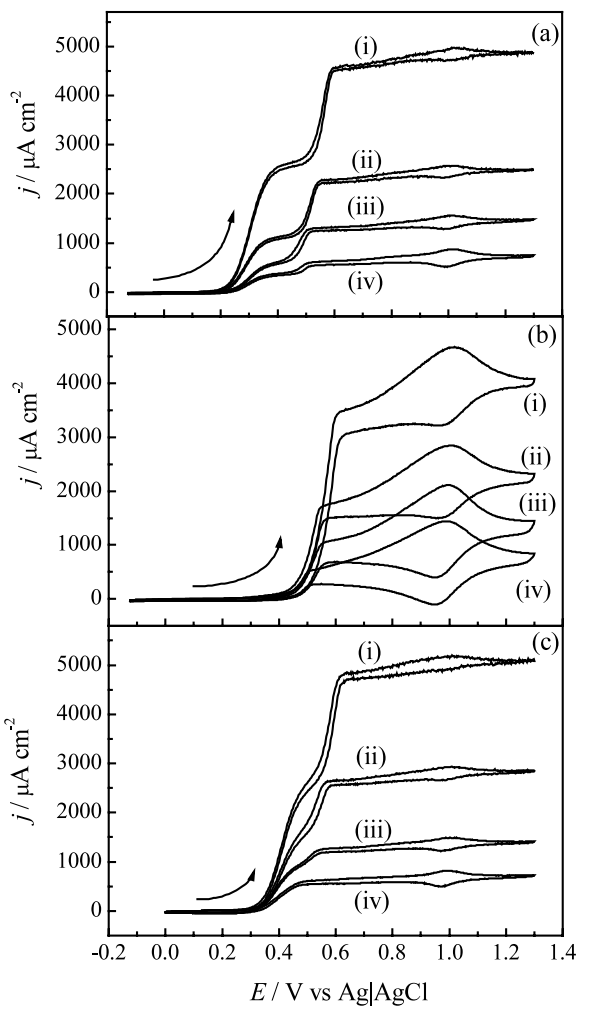

Fig. 4. Rotated disk voltammograms for thin and thick poly[Ni(saltMe)] films immersed in substrate $+0.1 \mathrm{~mol} \mathrm{dm}^{-3}$ TEAP $+\mathrm{CH}_{3} \mathrm{CN}$ solutions at $4500 \mathrm{rpm}$. (a) 1,1'-Dimethylferrocene, $\Gamma=4.1 \mathrm{nmol} \mathrm{cm}^{-2}$. (b) $1,1^{\prime}$-Dimethylferrocene, $\Gamma=47 \mathrm{nmol} \mathrm{cm}{ }^{-2}$. (c) Ferrocene, $\Gamma=4.6 \mathrm{nmol} \mathrm{cm}^{-2}$ : (i) 2.0 ; (ii) 1.0 ; (iii) 0.50 ; (iv) 0.25 $\mathrm{mmol} \mathrm{dm}{ }^{-3}$.
The only exception to this behaviour arises for ferrocene oxidation when the electrode is modified with a thin film and the electroactive solute concentra-

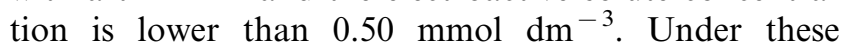
experimental conditions the steady-state voltammetry shows only one current density plateau (see Fig. 4c). Given the structural differences between both solutes, we may suggest an explanation for this observation based on the permeation rates of the species through the polymer film. For higher concentrations the direct oxidation of the substrate at the underlying Pt electrode is limited by the mobility of the solute across the film, and once sufficient mediated sites are electrochemically generated, some of the solute is oxidised by a second process mediated by the polymer film. For lower solute concentrations (for ferrocene at $c<0.50 \mathrm{mmol} \mathrm{dm}^{-3}$ ), solution hydrodynamic (not film permeation) is the rate limiting process: all the available solute can travel across the film, obviating the need for a second oxidation process mediated by the film. Since for $\mathrm{Me}_{2} \mathrm{Fc}$, even at $0.25 \mathrm{mmol} \mathrm{dm}^{-3}$, two current density plateaux are observed, we ascribe kinetic control to permeation, consistent with the larger $\mathrm{Me}_{2} \mathrm{Fc}$ species being less mobile than Fc.

\subsection{Diagnosis of charge transfer regimes}

The experimental results for the oxidation of $\mathrm{Me}_{2} \mathrm{Fc}$ and $\mathrm{Fc}$ at poly[Ni(saltMe)] modified electrodes raise two important properties of coated electrodes relevant to electrocatalysis: selective permeability and mediation capacity.

For the characterisation of membrane and mediation properties of these films we will analyse data from Figs. 3 and 4 using the Koutecky-Levich (KL) equation [32], and the experimental treatment of mediated charge transfer for polymer modified electrodes developed by Albery and Hillman [20,21].

\subsection{Ferrocene oxidation}

\subsubsection{First plateau}

Fig. 5a shows the Levich plots [25] for the oxidation of ferrocene at lower concentration $(c=0.26 \mathrm{mmol}$ $\left.\mathrm{dm}^{-3}\right)$ at thin poly[Ni(saltMe $\left.)\right]$ films $(\Gamma=2.6-6.2$ $\mathrm{nmol} \mathrm{cm}{ }^{-2}$ ), and at a bare Pt electrode. The $j_{\mathrm{L}}(\mathrm{I})$ versus $\omega^{1 / 2}$ plots are linear with zero intercept, clearly describing a fast electron transfer process where the rate limiting step is mass transport in solution. This is confirmed by the similarity of the substrate diffusion coefficient, $D_{\mathrm{S}}$ (obtained from the Levich plot) with and without the film (Table 1 and see above). Under these conditions ferrocene permeation into and through the poly[Ni(saltMe)] films is too fast to be measured.

Upon increasing the solute concentration, the limiting current density becomes lower than at the bare elec- 


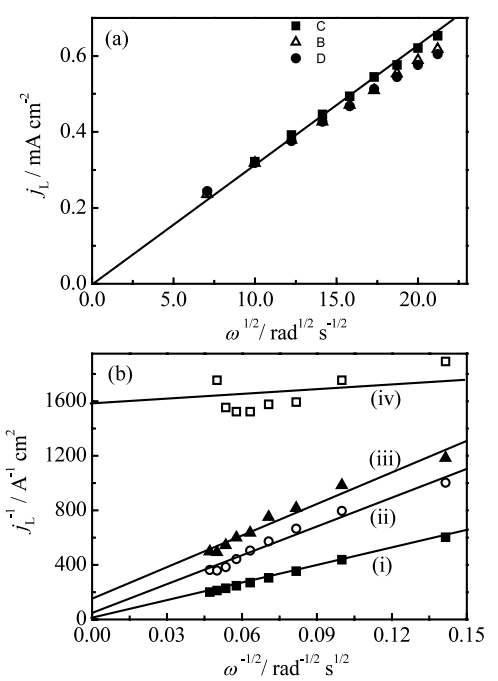

Fig. 5. (a) Levich plot, $j_{\mathrm{L}}(\mathrm{I})$ vs. $\omega^{1 / 2}$, for the first oxidation process of a $0.26 \mathrm{mmol} \mathrm{dm}^{-3}$ ferrocene $+0.1 \mathrm{~mol} \mathrm{dm}{ }^{-3} \mathrm{TEAP}+\mathrm{CH}_{3} \mathrm{CN}$ solution at: (ם) bare electrode, and poly[Ni(saltMe)] modified electrode with: $(\Delta) \Gamma=2.6 ;(\bigcirc) 6.2 \mathrm{nmol} \mathrm{cm}^{-2}$. The inserted line was obtained for the bare electrode. (b) KL plot, $j_{\mathrm{L}}(\mathrm{I})^{-1}$ vs. $\omega^{-1 / 2}$, for the oxidation of a $1.66 \mathrm{mmol} \mathrm{dm}{ }^{-3}$ ferrocene $+0.1 \mathrm{~mol} \mathrm{dm}{ }^{-3} \mathrm{TEAP}+\mathrm{CH}_{3} \mathrm{CN}$ solution: (i) bare electrode; poly[Ni(saltMe) $]$ modified electrode with: (ii) $\Gamma=$ 6.0 ; (iii) 6.6 ; and (iv) $68 \mathrm{nmol} \mathrm{cm}^{-2}$.

trode. This is reflected in the Levich plot as a deviation from linearity at higher rotation speeds. This suggests that some factor other than membrane diffusion is rate controlling. We now apply the KL equation [32]:

$\frac{1}{j_{\mathrm{L}}}=\frac{1}{0.62 n F D_{\mathrm{S}}^{2 / 3} v^{-1 / 6} c_{\mathrm{S}} \omega^{1 / 2}}+\frac{1}{n F k_{\mathrm{ME}}^{\prime} c_{\mathrm{S}}}$

where $k_{\mathrm{ME}}^{\prime}$ is the effective heterogeneous rate constant for the modified electrode, $c_{\mathrm{S}}$ is the solute bulk concentration, $D_{\mathrm{S}}$ is the diffusion coefficient of the substrate in solution, $v$ is the kinematic viscosity of the solution and all the other symbols have their usual meanings. According to the mechanism, there are various expressions for $k_{\mathrm{ME}}^{\prime}$ (Fig. 1) which we now explore.

As is seen in Fig. 5b, for a ferrocene concentration of $1.66 \mathrm{mmol} \mathrm{dm}^{-3}$, KL plots for oxidation at thin films show linear behaviour but with a non-zero intercept. This is consistent with the membrane model. Based on the Albery analysis [20,21] (see Fig. 1) and considering the first oxidation process as a direct reaction on the underlying Pt electrode, the limiting current density $j_{\mathrm{L}}(\mathrm{I})$ observed in the steady-state voltammogram for the oxidation of ferrocene $\left(c>0.5 \mathrm{mmol} \mathrm{dm}^{-3}\right)$ can be described as an $\mathrm{Et}_{\mathrm{S}}$ or $\mathrm{E} k_{\mathrm{e}}^{\prime}$ case. These correspond, respectively, to reaction rate control either by substrate mass transport through the film to the electrode or by the electron transfer rate at the Pt electrode | polymer interface. Discrimination between these two possibilities can be achieved on the basis of $k_{\mathrm{ME}}^{\prime}$ (calculated from the intercepts on the KL plots) as a function of the film thickness, $d$. For the $\mathrm{Et}_{\mathrm{s}}$ or $\mathrm{E} k_{\mathrm{e}}^{\prime}$ cases, respectively, $k_{\mathrm{ME}}^{\prime}$ should vary inversely or be independent of $d$ $[20,21,30,31]$. We assume that the electroactive sites are homogeneously distributed through the film so that film thickness is linearly related to the coulometrically determined electroactive coverage.

The $\log k_{\mathrm{ME}}^{\prime} \log \Gamma$ plot of Fig. 6 has a slope of -1.02 , unequivocally demonstrating that the first current plateau is controlled by substrate transport across the film. The data allow us to extract an experimental parameter describing the rate of substrate diffusion through the polymer (permeability), $\kappa D_{\text {SP. }}$ Since $d=$

Table 1

Kinetic parameters for the first oxidation process of ferrocene at poly[Ni(saltMe)] modified electrodes

\begin{tabular}{|c|c|c|c|c|}
\hline $10^{3} c_{\mathrm{S}} / \mathrm{mol} \mathrm{dm}^{-3}$ & $10^{9} \Gamma / \mathrm{mol} \mathrm{cm}^{-2}$ & $10^{5} D_{\mathrm{S}} / \mathrm{cm}^{2} \mathrm{~s}^{-1}$ & $10^{2} k_{\mathrm{ME}}^{\prime} / \mathrm{cm} \mathrm{s}^{-1}$ & $10^{10} \kappa D_{\mathrm{SP}} c_{\mathrm{Pol}} / \mathrm{mol} \mathrm{cm}^{-1} \mathrm{~s}^{-1}$ \\
\hline 0.26 & $\begin{array}{r}2.7 \\
6.3 \\
21.6 \\
70.0\end{array}$ & $\begin{array}{l}2.2 \\
2.2 \\
\mathrm{~b} \\
\mathrm{~b}\end{array}$ & $\mathrm{a}$ & a \\
\hline 0.53 & $\begin{array}{r}5.0 \\
9.3 \\
23.4 \\
55.4\end{array}$ & $\begin{array}{l}2.0 \\
1.9 \\
\mathrm{~b} \\
\mathrm{~b}\end{array}$ & a & a \\
\hline 1.03 & $\begin{array}{r}3.8 \\
6.5 \\
24.6 \\
62.2\end{array}$ & $\begin{array}{l}1.7 \\
1.6 \\
1.1 \\
b\end{array}$ & $\begin{array}{l}5.8 \\
2.5 \\
0.8 \\
\text { b }\end{array}$ & 2.7 \\
\hline 1.66 & $\begin{array}{r}6.0 \\
6.7 \\
21.8 \\
68.0\end{array}$ & $\begin{array}{l}1.4 \\
1.3 \\
1.0 \\
\mathrm{~b}\end{array}$ & $\begin{array}{l}12.0 \\
4.0 \\
1.3 \\
b\end{array}$ & 2.2 \\
\hline
\end{tabular}

${ }^{a}$ For this experimental conditions the mass transport is controlled by the hydrodynamic diffusion layer.

b $j_{\mathrm{L}}$ is independent of the electrode rotation rate. 


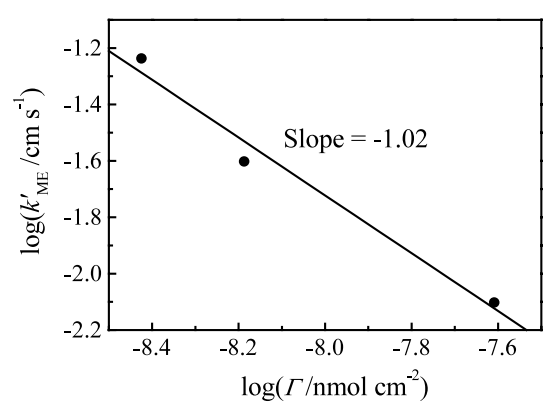

Fig. 6. Plot of $\log k_{\mathrm{ME}}^{\prime}$ vs. $\log \Gamma$, for the first ferrocene oxidation

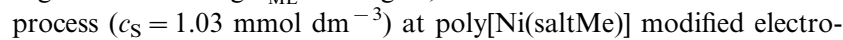
des.

$c_{\mathrm{Pol}} \times \Gamma$, where $c_{\mathrm{Pol}}$ is the electroactive site concentration, the permeability coefficient can be expressed as $\kappa D_{\mathrm{SP}} c_{\mathrm{Pol}}$ (Table 1).

From the slope of the KL plot presented in Fig. 5b it is also possible to estimate the diffusion coefficient of the electroactive solute in solution at the higher substrate concentrations. These values, presented in Table 1 , are experimentally indistinguishable from those obtained at the bare electrode, consistent with the model employed.

As we increase the polymer thickness, Fig. 5b (iv), the electroactive solute will diffuse more slowly within the film to reach the Pt electrode interface, allowing the film to achieve a conductive state, so that mediation of the electron transfer process begins to occur.

\subsubsection{Second plateau}

For thicker films, the process at more positive potentials produces the only observable limiting current. We attribute this oxidation process to $\mathrm{Fc}$ oxidation reaction mediated by the polymer active sites. To exploit this kinetic information we recall again the experimental test of the analysis reviewed in the literature $[20,21,30,31]$.

We can exclude the $\mathrm{St}_{\mathrm{e}}$ and $\mathrm{LSt}_{\mathrm{e}}$ cases, both controlled by electron transport between the Pt electrode and the film $\mid$ solution interfacial region, because the limiting current increases with rotation rate $[20,21]$. KL plots (see Fig. 7) for this second wave all show parallel linear behaviour with positive intercept. This allows us to eliminate the situation where the oxidation occurs in a reaction layer close to the electrode controlled by the reaction kinetics, the $\mathrm{LE}_{k}$ case. We must therefore compare the KL plots slopes and the constant $B(B=$ $\left.0.62 D_{\mathrm{S}}^{2 / 3} v^{1 / 6}\right)$ from the normalised KL equation [30,31];

$\frac{n F c_{\mathrm{S}}}{j_{\mathrm{L}}}=\frac{1}{B \omega^{1 / 2}}+\frac{1}{k_{\mathrm{ME}}^{\prime}}$

Using the diffusion coefficient estimated for this substrate (Table 1 ) we calculate $B=1.15 \times 10^{-3} \mathrm{~cm}$ $\mathrm{s}^{-1 / 2}\left(1 / B=868 \mathrm{~cm}^{-1} \mathrm{~s}^{1 / 2}\right)$. This latter value is somewhat higher than those calculated from the slopes of

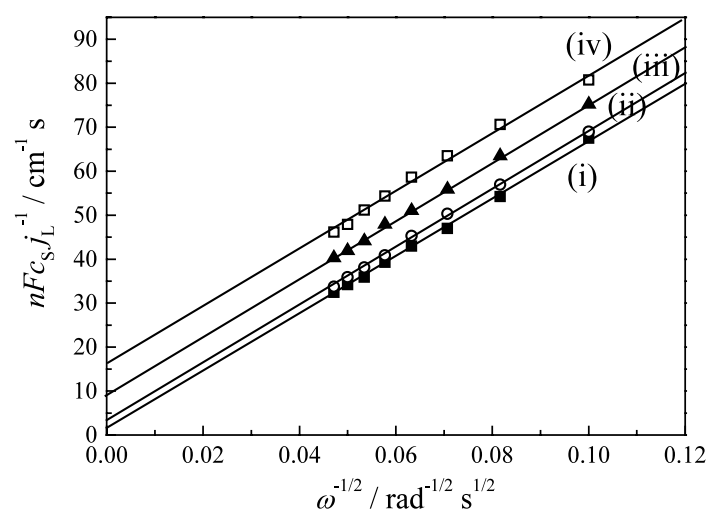

Fig. 7. KL plots for the second oxidation process of ferrocene $\left(c_{\mathrm{S}}=\right.$ $1.66 \mathrm{mmol} \mathrm{dm} \mathrm{dm}^{-3}$ ) in $0.1 \mathrm{~mol} \mathrm{\textrm {dm } ^ { - 3 }}$ TEAP $+\mathrm{CH}_{3} \mathrm{CN}$ solution at poly[Ni(saltMe)] modified electrodes of varying coverage: (i) $\Gamma=6.0$;

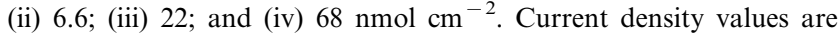
normalised with respect to the substrate concentration.

Fig. 7. The experimental values, $1 / B_{\exp }$, vary with substrate concentration $\left(1 / B_{\exp }=663 \mathrm{~cm}^{-1} \mathrm{~s}^{1 / 2}\right.$ for $c_{\mathrm{Fc}}=1.66 \mathrm{mmol} \mathrm{dm} \mathrm{dm}^{-3}$ and $1 / B_{\exp }=42 \mathrm{~cm}^{-1} \mathrm{~s}^{1 / 2}$ for $c_{\mathrm{Fc}}=1.03 \mathrm{mmol} \mathrm{dm}^{-3}$ ) which suggests that ferrocene oxidation occurs in a thin reaction layer away from the interfaces, where the exact location will be closer to the electrode or to the solution depending on whether the electron or the substrate transport dominates, respectively; this is the $\mathrm{LRZt}_{\mathrm{e}} \mathrm{t}_{\mathrm{s}}$ case. However, confirmation of the reaction zone and kinetic parameters controlling the reaction rate can be achieved by analysis of the $k_{\mathrm{ME}}^{\prime}$ dependence on film thickness.

Fig. 8 shows the logarithmic representation of $k_{\mathrm{ME}}^{\prime}$ versus $\Gamma$, for two different solute concentrations. For the highest substrate concentration (Fig. 8b), the plot clearly indicates a reciprocal dependence for these two parameters, as would be expected for a $\mathrm{LRZt}_{\mathrm{e}} \mathrm{t}_{\mathrm{s}}$ case. However, for the lowest concentration the slope is smaller than -1 , suggesting some change in the rate limiting process towards a thickness independent regime, such as $\mathbf{S} k^{\prime}$ or LSk (reaction at the film | solution interface, controlled by the surface reaction or layer reaction kinetics). The closely related $\mathrm{S} k^{\prime}$ or LS $k$ cases require the same value for $1 / B_{\exp }$ (either estimated from the slope of the KL plot or calculated from the substrate diffusion coefficient). The experimental results for the lowest concentration of ferrocene (Table 1) are consistent with this proposed case transition. In principle, the distinction between the two surface cases could be made based on the variation of $k_{\mathrm{ME}}^{\prime}$ with the electroactive site concentration $b_{0}$. However, for this type of film $b_{0}$ depends simultaneously on $d$ and $\Gamma$, and experimentally we were not able to vary the two parameters independently.

The mediated charge transfer reactions described as $\mathrm{LRZt}_{\mathrm{e}} \mathrm{t}_{\mathrm{s}}$ are rather unusual, as the rather fine balance between the rate of electron transport across the film and the rate of substrate transport is easily upset. 


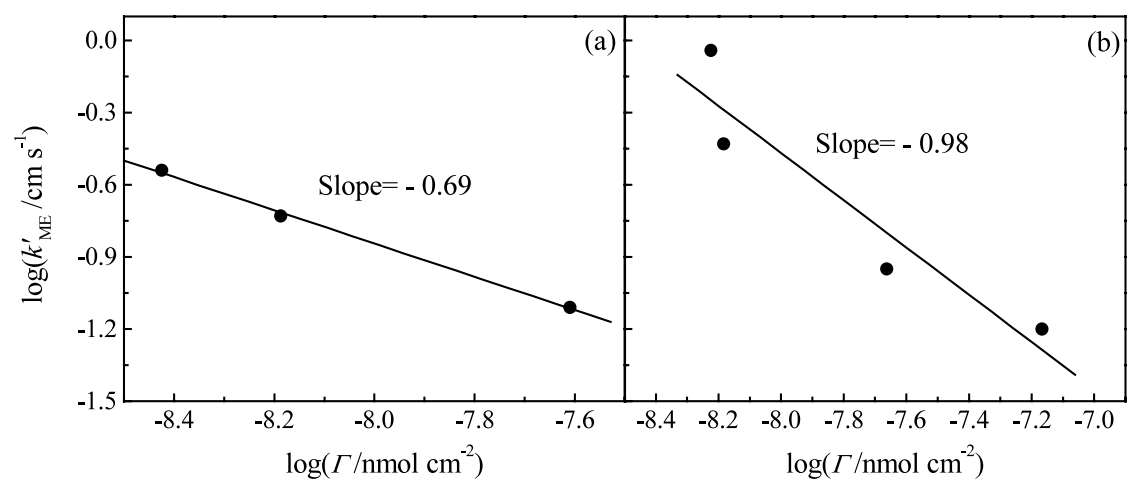

Fig. 8. Plots of $\log k_{\mathrm{ME}}^{\prime}$ vs. $\log \Gamma$, for the second oxidation process of ferrocene at poly[Ni(saltMe) $\operatorname{modified~electrodes.~(a)~} c_{\mathrm{Fc}}=1.03$; (b) $c_{\mathrm{Fc}}=1.66$ mmol dm ${ }^{-3}$.

Increasing the concentration of active sites will shift the reaction zone towards the outer interface (solution), while increasing the substrate concentration will shift it towards the inner interface (underlying electrode).

\subsection{1,1'-Dimethylferrocene oxidation}

In contrast to the behaviour seen for ferrocene, the steady-state voltammograms for the oxidation of this substrate always show two limiting current plateaux, $j_{\mathrm{L}}(\mathrm{I})$ and $j_{\mathrm{L}}(\mathrm{II})$, that correspond to the direct and polymer-mediated reactions, respectively. The analysis we apply is analogous to that used for Fc oxidation (see above).

\subsubsection{First plateau}

Levich plots for the first plateau are non-linear, limiting the oxidation mechanism control to film permeation or reaction kinetics, both requiring a further analysis through the KL equation (Fig. 9). These plots show linear behaviour with positive intercepts, suggesting film transport rate control: the heterogeneous rate constant for the modified electrode is inversely propor- tional to the electroactive coverage/film thickness, establishing substrate transport as the rate limiting step (the $\mathrm{Et}_{\mathrm{S}}$ case), for the first oxidation process of $1,1^{\prime}$-dimethylferrocene at thin poly[Ni(saltMe)] modified electrodes.

The $D_{\mathrm{S}}$ values estimated from KL plots (Table 2) are, within experimental error, the same as those obtained for $\mathrm{Me}_{2} \mathrm{Fc}$ oxidation at the bare Pt electrode. Table 2 also includes the film permeability parameter, $\kappa D_{\mathrm{SP}} c_{\mathrm{Pol}}$, calculated based on the $k_{\mathrm{ME}}^{\prime}$ equations (see Fig. 1). Comparing the values obtained for both substrates, we can conclude that ferrocene is transported more rapidly across the poly[Ni(saltMe)] film than 1,1'-dimethylferrocene. However, we cannot distinguish whether this is due to a larger partition coefficient $(\kappa)$ or to a larger diffusion coefficient $\left(D_{\mathrm{SP}}\right)$.

\subsubsection{Second plateau}

The second limiting current density $\left(j_{\mathrm{L}}(\mathrm{II})\right)$ observed during the oxidation of 1,1'-dimethylferrocene with poly[Ni(saltMe)] modified electrode occurs at $E_{(\mathrm{II})}=$ $0.56 \mathrm{~V}$, where the polymer is still mainly in the reduced (non-conducting) form.
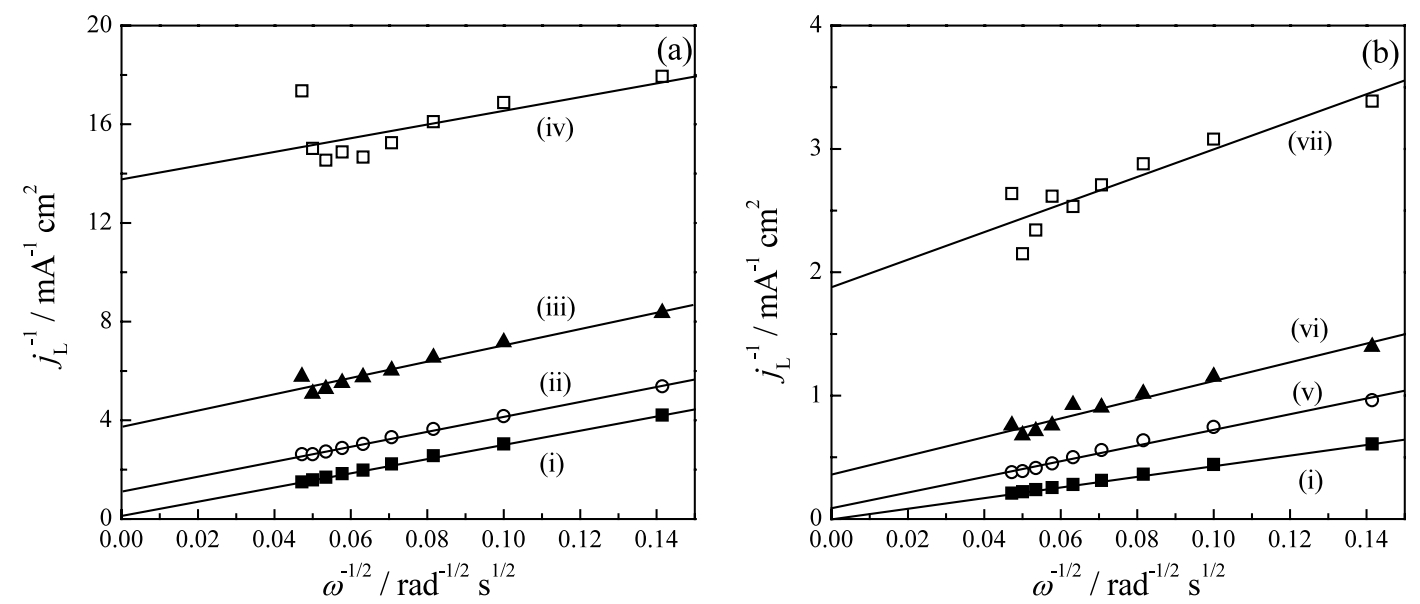

Fig. 9. KL plots for the second oxidation process of a 1,1'-dimethylferrocene +0.1 mol $\mathrm{dm}^{-3} \mathrm{TEAP}+\mathrm{CH}_{3} \mathrm{CN}$ solution: (i) bare electrode;

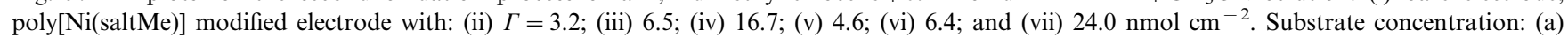
$c_{\mathrm{Me}_{2} \mathrm{Fc}}=0.29$; (b) $c_{\mathrm{Me}_{2} \mathrm{Fc}}=2.10 \mathrm{mmol} \mathrm{dm}^{-3}$. 
Table 2

Kinetic parameters for the first oxidation process of $1,1^{\prime}$-dimethylferrocene at poly[Ni(saltMe)] modified electrodes

\begin{tabular}{|c|c|c|c|c|}
\hline $10^{3} c_{\mathrm{S}} / \mathrm{mol} \mathrm{dm}^{-3}$ & $10^{9} \Gamma / \mathrm{mol} \mathrm{cm}^{-2}$ & $10^{5} D_{\mathrm{S}} / \mathrm{cm}^{2} \mathrm{~s}^{-1}$ & $10^{2} k_{\mathrm{ME}}^{\prime} / \mathrm{cm} \mathrm{s}^{-1}$ & $10^{10} \kappa D_{\mathrm{SP}} c_{\mathrm{Pol}} / \mathrm{mol} \mathrm{cm}^{-1} \mathrm{~s}^{-1}$ \\
\hline 0.29 & $\begin{array}{r}3.2 \\
6.5 \\
16.7\end{array}$ & $\begin{array}{l}2.2 \\
1.9 \\
2.5\end{array}$ & $\begin{array}{l}3.1 \\
1.0 \\
0.3\end{array}$ & 1.1 \\
\hline 0.50 & $\begin{array}{r}4.6 \\
9.3 \\
23.4\end{array}$ & $\begin{array}{l}1.9 \\
1.4 \\
1.5\end{array}$ & $\begin{array}{l}2.9 \\
1.3 \\
1.2\end{array}$ & 1.0 \\
\hline 1.07 & $\begin{array}{r}4.4 \\
5.5 \\
23.6\end{array}$ & $\begin{array}{l}1.1 \\
1.3 \\
1.2\end{array}$ & $\begin{array}{l}3.1 \\
2.2 \\
0.3\end{array}$ & 1.5 \\
\hline 2.10 & $\begin{array}{r}4.6 \\
6.4 \\
24.0\end{array}$ & $\begin{array}{l}1.2 \\
0.9 \\
0.7\end{array}$ & $\begin{array}{l}3.6 \\
1.3 \\
0.3\end{array}$ & 1.7 \\
\hline
\end{tabular}

The KL plots for this second wave, Fig. 10, are linear but with non-zero intercepts. We shall now show that we can ascribe the reaction rate control to the polymer film, and exclude the $\mathrm{LSt}_{\mathrm{e}}, \mathrm{St}_{\mathrm{e}}$ and LE $k$ cases.

Using the solution diffusion coefficient of $\mathrm{Me}_{2} \mathrm{Fc}$, we calculate $B=1.11 \times 10^{-3} \mathrm{~cm} \mathrm{~s}^{-1 / 2}$, essentially identical to the experimental value obtained from the slope of the $\mathrm{KL}$ plot, $B_{\exp }=1.13 \times 10^{-3} \mathrm{~cm} \mathrm{~s}^{-1 / 2}$. At high concen-

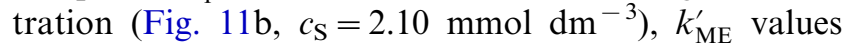
(see Fig. 11) are inversely proportional to the coverage $\left(\mathrm{d}\left[\log k_{\mathrm{ME}}^{\prime}\right] / \mathrm{d}[\log \Gamma] \approx-1\right)$. With decreasing solute concentration (Fig. 11a, $c_{\mathrm{S}}=1.07 \mathrm{mmol} \mathrm{dm}^{-3}$ ), this value decreases. Based on the Albery analysis [20,21], this behaviour can be interpreted in terms of a changeover in the rate limiting process: for higher $\mathrm{Me}_{2} \mathrm{Fc}$ concentrations the reaction is controlled by substrate transport through the film and occurs close to the underlying electrode interface, $\mathrm{LEt}_{\mathrm{S}}$ case. As the substrate concentration decreases, $k_{\mathrm{ME}}^{\prime}$ becomes essentially independent of the film thickness/electroactive coverage, corresponding to the reaction occurring at the film | solution interface or close to it, and controlled by the electron

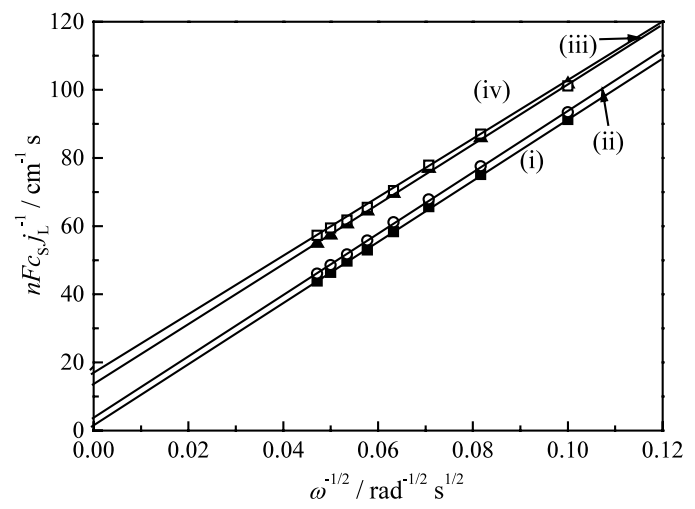

Fig. 10. KL plots for the first oxidation process of 1,1'-dimethylferrocene $\left(c_{\mathrm{S}}=2.10 \mathrm{mmol} \mathrm{dm}^{-3}\right)$ in $0.1 \mathrm{~mol} \mathrm{dm}^{-3} \mathrm{TEAP}+\mathrm{CH}_{3} \mathrm{CN}$ solution at poly[Ni(saltMe)] modified electrodes of varying coverage: (i) $\Gamma=4.6$; (ii) 6.4 ; (iii) 24 ; and (iv) $54 \mathrm{nmol} \mathrm{cm}^{-2}$. transfer kinetics, i.e. either of the closely related $\mathrm{S} k^{\prime}$ or LS $k$ cases.

\section{Discussion}

The mechanistic analysis for polymer-mediated oxidation revealed a dependence of the reaction zone where the process takes place on the substrate concentration. For low substrate concentrations, the maximum electron flux across the film exceeds the substrate flux across the film, so the reaction zone is pinned to the film $\mid$ solusolution interface. Under kinetic control this corresponds to the $\mathrm{S} k^{\prime}$ case, or to the closely related LS $k$ case. As the substrate concentration increases, so the demand for electrons increases and the electron transport rate eventually becomes rate limiting. Confirmation of the locations of these reaction zones is obtained via the ratio of electron and substrate fluxes [20,21]:

$\frac{J_{\mathrm{e}}}{J_{\mathrm{S}}}=\frac{D_{\mathrm{e}} b_{0}}{\kappa D_{\mathrm{SP}} c_{\mathrm{S}}}$

where $D_{\mathrm{e}}$ is the electron diffusion rate through the polymer film and $b_{0}$ is the electroactive site concentration at the potential at which the reaction occurs.

For ferrocene, $J_{\mathrm{e}} / J_{\mathrm{S}}$ can be estimated as follows: (i) $\kappa D_{\mathrm{SP}}=1.17 \times 10^{-7} \mathrm{~cm}^{2} \mathrm{~s}^{-1}$ (obtained from Table 1 , with $c_{\mathrm{Pol}}=2.1 \times 10^{-3} \mathrm{~mol} \mathrm{~cm}^{-3}$ obtained from ellipsometry [33]); (ii) $D_{\mathrm{e}}=2.1 \times 10^{-8} \mathrm{~cm}^{2} \mathrm{~s}^{-1}$ [18]; (iii) $c_{\mathrm{Fc}}=$ $1.34 \times 10^{-6} \mathrm{~mol} \mathrm{~cm}^{-3}$ (a typical value from Table 1); (iv) we assume no changes in the polymer permeability properties with potential; and (v) we approximate $b_{0}$ at the second oxidation process potential as $1 \%$ of the entire polymer electroactive sites concentration. We obtain $J_{\mathrm{e}} / J_{\mathrm{S}} \approx 2.8$. Despite the difficulty in ascertaining the $b_{0}$ value accurately at low film redox conversion, this ratio clearly demonstrates the same order of magnitude for electron and substrate fluxes typical of the LRZt $t_{\mathrm{e}} \mathrm{t}_{\mathrm{S}}$ 


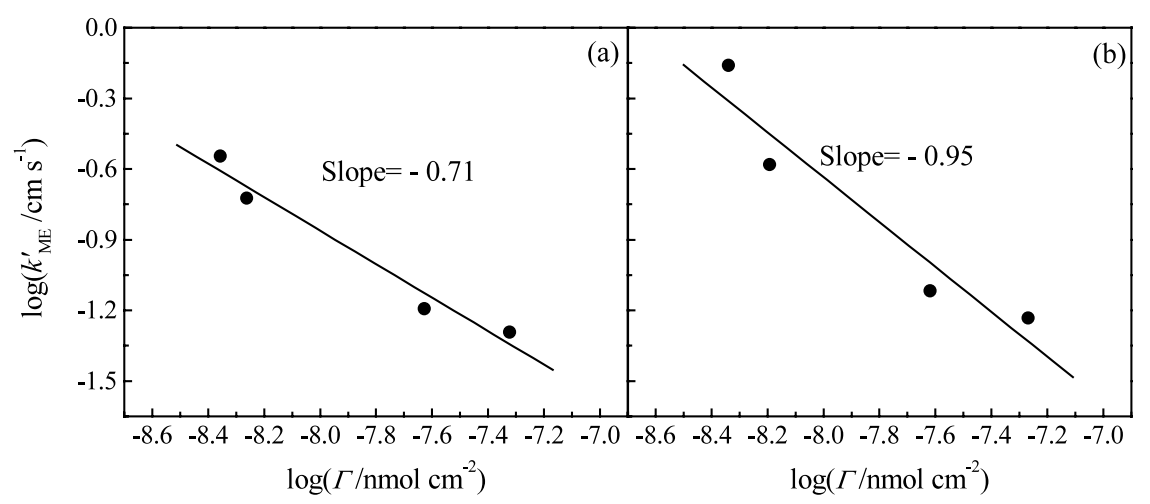

Fig. 11. Plot of $\log k_{\mathrm{ME}}^{\prime}$ Vs. $\log \Gamma$, for the second oxidation process of $1,1^{\prime}$-dimethylferrocene at poly[Ni(saltMe)] modified electrodes. (a) $c_{\mathrm{Me}_{2} \mathrm{Fc}}=$ 1.07; (b) $c_{\mathrm{Me}_{2} \mathrm{Fc}_{\mathrm{c}}}=2.10 \mathrm{mmol} \mathrm{dm}^{-3}$.

case. However, small changes in conditions move the reaction layer from the outer to the inner part of the polymer film.

For 1,1'-dimethylferrocene: (i) $\kappa D_{\mathrm{SP}}=6.19 \times 10^{-8}$ $\mathrm{cm}^{2} \mathrm{~s}^{-1}$ (obtained from Table 2, with $c_{\mathrm{Pol}}=2.1 \times$ $\left.10^{-3} \mathrm{~mol} \mathrm{~cm}{ }^{-3}\right)$; (ii) $D_{\mathrm{e}}=2.1 \times 10^{-8} \mathrm{~cm}^{2} \mathrm{~s}^{-1}$ [18]; (iii) $c_{\mathrm{Me}_{2} \mathrm{Fc}}=0.99 \times 10^{-6} \mathrm{~mol} \mathrm{~cm}{ }^{-3}$ (a typical value from Table 2); (iv) we assume no changes in the polymer permeability properties with potential; and (v) we estimate $b_{0}$ to be lower than $0.1 \%$ of the entire polymer electroactive sites concentration (since the second oxidation process occurs at a potential where the film is barely conducting). This yields $J_{\mathrm{e}} / J_{\mathrm{S}}<1$, i.e. the substrate flux is higher than the electron flux, shifting the reaction layer close to the $\mathrm{Pt}$ electrode $\mid$ film interface, i.e. towards the LEts case.

Comparison between values of $\kappa D_{\mathrm{SP}}$ for ferrocene and 1,1'-dimethylferrocene (Tables 1 and 2) apparently suggests that the diffusion rate across the film is higher for ferrocene. However, for 1,1'-dimethylferrocene, mediated oxidation occurs close to the underlying electrode interface, suggesting the opposite. For the reaction zone to be considered as a substrate diffusion rate indicator it would be necessary to keep all the film parameters constant. However, as indicated above, the mediated $\mathrm{Me}_{2} \mathrm{Fc}$ oxidation reaction occurs at less positive potentials than for $\mathrm{Fc}$, and consequently the polymer electroactive site concentration at the potential where the mediated reaction occurs $\left(b_{0}\right)$ is smaller when the $\mathrm{Me}_{2} \mathrm{Fc}$ is oxidised, contributing to a slower electron transport rate through the film.

Lower limits for the rate constants for the mediated reactions $(k)$ for both substrates can also be estimated from Eqs. (1a) and (1b). From Eq. (1b), for ferrocene $k>5 \times 10^{9} \mathrm{~mol}^{-1} \mathrm{~cm}^{3} \mathrm{~s}^{-1}$, using all the known parameter values (see above) and $d \approx 100 \mathrm{~nm}$ [33] which is much greater than $X_{\mathrm{d}}$. A similar calculation for 1,1'dimethylferrocene, using Eq. (1a), gives $k>2 \times 10^{10}$ $\mathrm{mol}^{-1} \mathrm{~cm}^{3} \mathrm{~s}^{-1}$. These values show that mediated reactions within poly[Ni(saltMe)] modified electrodes are very high, suggesting that this polymer is a promising electrocatalyst.

In the above diagnosis, we deduced the mechanistic cases for ferrocene and 1,1'-dimethylferrocene oxidations on the basis of the relative variations of the heterogeneous rate constant $\left(k_{\mathrm{ME}}^{\prime}\right)$ with the experimental parameters. Although all the conclusions are individually internally consistent, we can apply a further check on consistency, as follows.

Our diagnosis identified individual regions (mechanistic cases) and showed how the variations of $k_{\mathrm{ME}}^{\prime}$ with $\Gamma$ and $b_{0}$ within a limited region of parameter space were in accord with the appropriate expressions for $k_{\mathrm{ME}}^{\prime}$ in Fig. 1. However, extended variation of experimental parameters can ultimately move the system into a different mechanistic case. The allowed mechanistic shifts are defined by the case diagram, i.e. they can only be into an adjacent case and by an $\left(X_{0}, X_{\mathrm{d}}\right)$ translation in the appropriate direction. In short, we have so far only looked at variations in $k_{\mathrm{ME}}^{\prime}$ within a given case, but now examine variations between cases as a stringent check on the validity of the analysis. To do this, it is helpful to view the case diagram employing normalised parameters in terms of the 'signpost' (Fig. 12) showing the effects of the variables.

First, let us consider the effect of film thickness $(d)$, effectively polymer coverage $(\Gamma)$. Increasing $d$ (or $\Gamma$ ) moves the system downwards and to the left on a line of unit slope (a 'southwesterly' direction). If one is initially in any of the $\mathrm{LSt}_{\mathrm{e}}, \mathrm{LRZt}_{\mathrm{e}} \mathrm{t}_{\mathrm{S}}$ or $\mathrm{LEt}_{\mathrm{S}}$ cases, there will be no change. The only way out of these cases is by a sufficiently large decrease in film thickness that transport (of electrons and/or substrate) is no longer rate limiting; in the present case this would require nearmonolayer films, which we do not study.

Second, let us consider the effect of substrate concentration in solution $\left(c_{\mathrm{S}}\right)$. Increasing concentration corresponds to translation to the left in the case diagram. For ferrocene oxidation, Fig. 8 showed that high solution concentration (with consequent thinner reaction layer $X_{0}$ ) yielded the $\mathrm{LRZt}_{\mathrm{e}} \mathrm{t}_{\mathrm{S}}$ case, but that 
a)

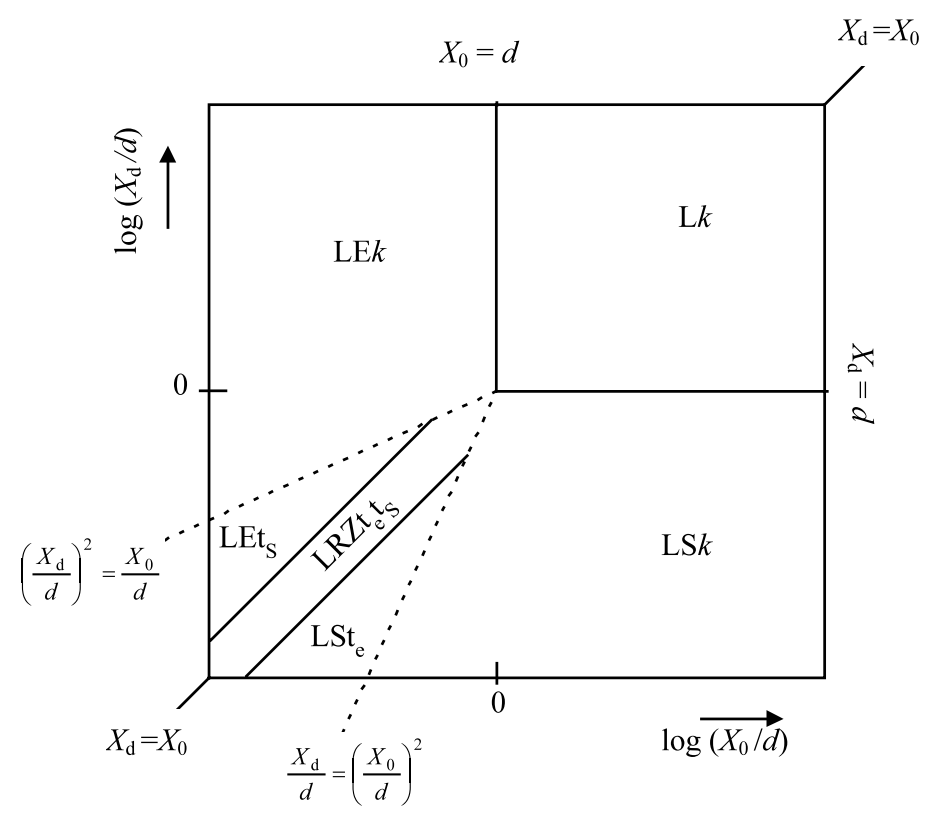

b)

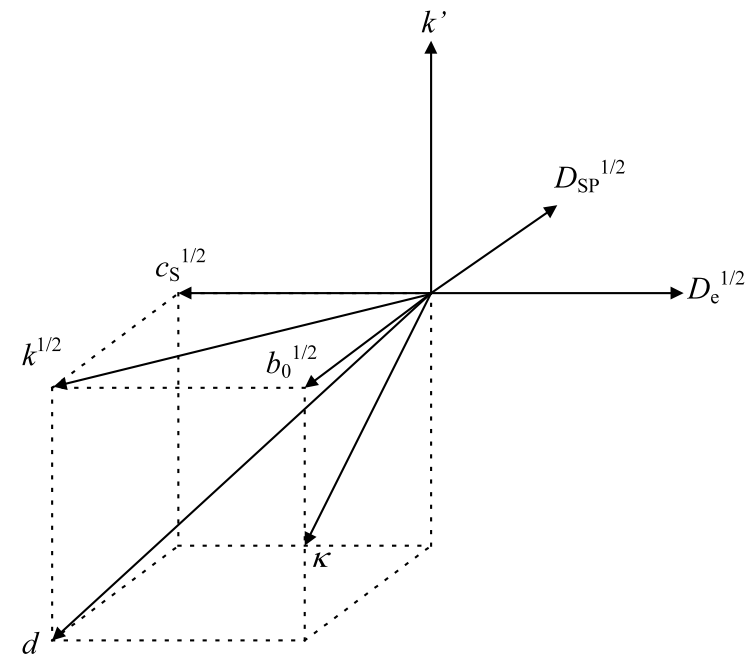

Fig. 12. (a) Reaction zone scheme diagnosed for the oxidations of $1,1^{\prime}$-dimethylferrocene and ferrocene at poly[Ni(saltMe)] modified electrodes via the second (mediated) oxidation process. (b) Effect of raw variables in the determination of mechanistic cases. Reproduced from Ref. [21].

lower solution concentration (and thus thicker reaction layer $X_{0}$ ) moved the system away from a transport controlled regime. Inspection of the case diagram suggests that, moving right from the $\mathrm{LRZt}_{\mathrm{e}} \mathrm{t}_{\mathrm{s}}$ case, one encounters the $\mathrm{LSt}_{\mathrm{e}}$ and $\mathrm{LS} k$ cases. On the basis of the deduced proximity of the system to the origin it is entirely reasonable that the LS $k$ case is approached, although the proximity of several small mechanistic zones makes 'clean' behaviour hard to find. For 1,1'dimethylferrocene, decreasing the solution reactant concentration was deduced to take the system from the $\mathrm{LEt}_{\mathrm{S}}$ case to the LSk case, traversing the rather narrow $\mathrm{LRZt}_{\mathrm{e}} \mathrm{t}_{\mathrm{S}}$ region (in the vicinity of the origin). Again this is reasonable.

Finally, we consider the effect of varying mediator concentration in the film $\left(b_{0}\right)$. Here, for each of the solution reactants, we made measurements of mediated charge transfer only at a single potential, i.e. a single mediator concentration within the film. However, for the two substrates, the measurements were made at different potentials, i.e. different values of $b_{0}$. This was a consequence of the different mediated charge transfer rate constants: for 1,1'-dimethylferrocene the rate constant was greater, so a smaller concentration of mediator (available at a less positive potential) was required to achieve the limiting flux. Although the effect of $k$ is neutral in this region of the case diagram (a 'southwesterly' shift, not affecting the $\mathrm{LSt}_{\mathrm{e}}, \mathrm{LRZt}_{\mathrm{e}} \mathrm{t}_{\mathrm{S}}$ or $\mathrm{LEt}_{\mathrm{S}}$ cases), a lower value of $b_{0}$ corresponds to an 'upward' shift in the projection of Fig. 12a. This would move one from the LRZt $t_{\mathrm{e}} \mathrm{t}_{\mathrm{S}}$ zone (seen for ferrocene) into the $\mathrm{LEt}_{\mathrm{S}}$ zone (seen for 1,1'-dimethylferrocene). Again, this is entirely consistent with the analysis.

\section{Conclusions}

For thin films, both substrate oxidations follow two mechanisms, according to the applied potential. The first, corresponding to the direct (unmediated) reaction on the underlying electrode, is controlled by the substrate transport through the film, the $\mathrm{Et}_{\mathrm{s}}$ case. This process occurs at a potential where the polymer is still inactive. For ferrocene concentrations lower than 0.5 mmol dm ${ }^{-3}$, the direct reaction is the only observable process and film transport is so fast that the reaction is controlled by solute solution diffusion, quantified via $D_{\mathrm{S}}$. The second substrate oxidation process, at a higher potential than reaction at the bare electrode, is the only substrate oxidation mechanism observed upon increasing the polymer thickness. This process is assigned to polymer-mediated reaction.

Experimental conditions maximising mediated charge transfer processes at poly[Ni(saltMe)] modified electrodes are: (i) thick films, to avoid the unmediated reaction on the underlying electrode; and (ii) moderate substrate concentrations, for the reaction to occur in a polymer reaction layer as wide as possible $\left(0.5-1.5 \mathrm{mmol} \mathrm{dm}^{-3}\right.$ for the substrates used here). 
In all the mediated charge transfer situations (reactants and conditions) explored, $X_{0} / d$ and $X_{\mathrm{d}} / d$ were less than unity. This places the systems in the lower left hand corner of Albery's mechanistic case diagram (Fig. 12a). It is interesting to point out that the mechanistic studies originally used to test this model tended to occupy the other three quadrants (upper and/or right hand half) of the case diagram. That was because the second order rate constants $(k)$ associated with the mediated reactions in the film were relatively low (see Eqs. (1a) and (1b)), and because the films used were very compact, so that the substrate diffusion coefficient was low. In the present study, the much faster rate constants necessarily decrease the reaction layer thicknesses and the more open film structure results in relatively similar effective diffusion coefficients for the substrate and electrons. Consequently, we have validated a relatively unexplored region of the case diagram, in the vicinity of the rather unusual $\mathrm{LRZt}_{\mathrm{e}} \mathrm{t}_{\mathrm{s}}$ case. Previously, this region of the case diagram was viewed as unlikely to be encountered, given the relatively small fraction of the diagram it occupies and its rather stringent requirements-fast kinetics and balanced electron and substrate diffusion fluxes. However, upon reflection we point out that this is a practically important case because these requirements are exactly those one would specify for a useful electrocatalytic system.

\section{Acknowledgements}

This work was partially supported by the 'Fundação para a Ciência e Tecnologia', Lisboa, Portugal, through Project POCTI/32831/QUI/2000.

\section{References}

[1] B. de Castro, C. Freire, Inorg. Chem. 29 (1990) 5113.

[2] M.A.A.F. de C.T. Carrondo, B. de Castro, A.M. Coelho, D. Domingues, C. Freire, J. Morais, Inorg. Chim. Acta 205 (1993) 157.

[3] F. Azevedo, M.A.A.F. de C.T. Carrondo, B. de Castro, M. Convery, D. Domingues, C. Freire, M.T. Duarte, K. Nielsen, I.C. Santos, Inorg. Chim. Acta 219 (1994) 43

[4] B. de Castro, C. Freire, J. Chem. Soc. Dalton Trans. (1998) 1491.
[5] B. de Castro, C. Freire, Polyhedron 17 (1998) 4227.

[6] I.C. Santos, M. Vilas-Boas, F. Piedade, C. Freire, M. Teresa Duarte, B. de Castro, Polyhedron 19 (2000) 655.

[7] K.A. Goldsby, J. Coord. Chem. 19 (1988) 83.

[8] K.A. Goldsby, J.K. Blaho, L.A. Hoferkamp, Polyhedron 8 (1989) 113.

[9] P. Audebert, P. Capdevielle, M. Maumy, New J. Chem. 15 (1991) 235.

[10] P. Audebert, P. Capdevielle, M. Maumy, Synth. Met. 43 (1991) 3049.

[11] P. Audebert, P. Capdevielle, M. Maumy, New J. Chem. 16 (1992) 697.

[12] P. Audebert, P. Hapiot, P. Capdevielle, M. Maumy, J. Electroanal. Chem. 338 (1992) 269.

[13] C.E. Dahm, D.G. Peters, J. Simonet, J. Electroanal. Chem. 410 (1996) 163.

[14] C.E. Dahm, D.G. Peters, Anal. Chem. 66 (1994) 3117.

[15] F. Bedioui, E. Labbe, S. Gutierrezgranados, J. Devynck, J. Electroanal. Chem. 301 (1991) 267.

[16] M. Vilas Boas, C. Freire, B. de Castro, P.A. Christensen, A.R. Hillman, Inorg. Chem. 36 (1997) 4919.

[17] M. Vilas Boas, C. Freire, B. de Castro, P.A. Christensen, A.R. Hillman, Chem. Eur. J. 7 (2001) 139.

[18] M. Vilas Boas, C. Freire, B. de Castro, A.R. Hillman, J. Phys. Chem. Sect. B 102 (1998) 8533.

[19] M. Vilas-Boas, M.J. Henderson, C. Freire, A.R. Hillman, E. Vieil, Chem Eur. J. 6 (2000) 1160

[20] W.J. Albery, A.R. Hillman, R.S.C. Ann. Rep. C 78 (1981) 377.

[21] W.J. Albery, A.R. Hillman, J. Electroanal. Chem. 170 (1984) 27.

[22] C.P. Andrieux, J.M. Dumas-Bouchiat, J.M. Savéant, J. Electroanal. Chem. 131 (1982) 1.

[23] C.P. Andrieux, J.M. Savéant, J. Electroanal. Chem. 134 (1982) 163.

[24] F.C. Anson, J.M. Savéant, K. Shigehara, J. Phys. Chem. 87 (1983) 214.

[25] V.G. Levich, Physiochemical Hydrodynamics, Prentice-Hall, Englewood Cliffs, 1962, p. 296

[26] T. Ikeda, R. Schmehl, P. Denisevich, K. Willman, R.W. Murray, J. Am. Chem. Soc. 104 (1982) 2683.

[27] S.G. Yan, J.T. Hupp, J. Electroanal. Chem. 397 (1995) 119.

[28] T. Kuwana, D.E. Bublitz, G.J. Hom, J. Am. Chem. Soc. 82 (1960) 5811.

[29] A.F. Diaz, F.A. Orozco-Rosales, J. Paredon-Rosales, K.K. Kanazawa, J. Electroanal. Chem. 103 (1979) 283.

[30] A.R. Hillman, in: R.G. Linford (Ed.), Electrochemical Science and Technology of Polymers (Chapters 5 and 6), Elsevier Applied Science, London, 1987, p. 103, 241.

[31] M.E.G. Lyons, Electroactive Polymer Electrochemistry. Part 1: Fundamentals, Plenum, New York, 1994, p. 247.

[32] J. Koutecky, V.G. Levich, Zh. Fiz. Khim. 32 (1956) 1565.

[33] M. Vilas-Boas, J. Abel, C. Freire, P. Christensen, A. Hamnett, unpublished results. 